\title{
EDUCAÇÃO E PANDEMIA: O ENSINO FUNDAMENTAL ANOS FINAIS EM UM SISTEMA DE ENSINO
}

\author{
EDUCACIÓN Y PANDEMIA: LOS ÚLTIMOS AÑOS DE LA EDUCACIÓN PRIMARIA \\ EN UN SISTEMA EDUCATIVO
}

\section{EDUCATION AND PANDEMIC: THE FINAL YEARS OF ELEMENTARY SCHOOL IN AN EDUCATION SYSTEM}

\author{
Fernando Damião de PAULA ${ }^{1}$ \\ Marcos Cesar Rodrigues de MIRANDA²
}

RESUMO: A pesquisa destaca as alterações nos processos educacionais, durante o isolamento social provocado pela pandemia da COVID-19, buscando evidências de novos processos adotados em um SE privado, com mais de 800 escolas na EB, com recorte no EFAF. O objetivo é descrever e analisar os procedimentos do SE para promover o ensino e aprendizagem no período pandêmico. A metodologia utilizada foi a pesquisa documental. Analisou-se as ações do SE na pandemia em apoio as unidades escolares. Focando o planejamento pedagógico, alinhamento com a $\mathrm{BNCC}$ e as práticas pedagógicas durante o ERE, gestão do EH e MA's aplicadas, visando promover aprendizagem de qualidade, satisfação de usabilidade e engajamento dos recursos digitais. Averiguou-se que no período 2019/2020 houve baixa utilização do todo ecossistema digital do SE e que foi necessário ter uma curva de aprendizagem para que usuários tivessem mais autonomia para aumentarem a utilização de forma exponencial no ano seguinte.

PALAVRAS-CHAVE: COVID-19. Educação híbrida. Tecnologias educacionais. Objetos digitais de aprendizagem. Plataformas digitais.

RESUMEN: La investigación destaca los cambios en los procesos educativos, durante el aislamiento social causado por la pandemia de COVID-19, buscando evidencias de los nuevos procesos adoptados en una SE privada, con más de 800 escuelas en EB, con un recorte en EFAF. El objetivo es describir y analizar los procedimientos de SE para promover la enseñanza y el aprendizaje en el periodo de pandemia. La metodología utilizada fue la investigación documental. Analizamos las actuaciones de la SE en la pandemia en apoyo de las unidades escolares. Centrándose en la planificación pedagógica, la alineación con el BNCC y las prácticas pedagógicas durante el ERE, la gestión del EH y el MA aplicados, con el objetivo de promover la calidad del aprendizaje, la satisfacción de la usabilidad y el compromiso de los recursos digitales. Se constató que en el periodo 2019/2020 había un bajo uso de todo el ecosistema digital de la SE y que era necesaria una curva de aprendizaje para

\footnotetext{
${ }^{1}$ Programa de Educação Continuada em Economia e Gestão de Empresas (PECEGE), Universidade de São Paulo (USP/ESALQ), Piracicaba - SP - Brasil. Especialização em Gestão Escolar (PECEGE/USP/ESALQ). ORCID: https://orcid.org/0000-0003-4300-3538. E-mail: professor.fernandodepaula@gmail.com

${ }_{2}^{2}$ Programa de Educação Continuada em Economia e Gestão de Empresas (PECEGE), Universidade de São Paulo (USP/ESALQ), Piracicaba - SP - Brasil. Pesquisador Associado. Mestrado em Química (UFSCAR). ORCID: https://orcid.org/0000-0002-4442-9971. E-mail: fernando.paula@pearson.com
}

RPGE- Revista on line de Política e Gestão Educacional, Araraquara, v. 25, n. 3, p. 2098-2116, set./dez. 2021. e-ISSN: 1519-9029 DOI: https://doi.org/10.22633/rpge.v25i3.15492 
que los usuarios tuvieran más autonomía para aumentar el uso exponencialmente en el año siguiente.

PALABRAS CLAVE: COVID-19. Educación híbrida. Tecnologías educativas. Objetos digitales de aprendizaje. Plataformas digitales.

ABSTRACT: The research highlights the changes in educational processes, during the social isolation caused by the pandemic of COVID-19, looking for evidence of new processes adopted in a private SE, with more than 800 schools in EB, with a cut in EFAF. The objective is to describe and analyze the SE procedures to promote teaching and learning in the pandemic period. The methodology used was documentary research. We analyzed the SE actions during the pandemic in support of school units. Focusing on pedagogical planning, alignment with the BNCC and pedagogical practices during the ERE, management of the EH and applied MA's, aiming to promote quality learning, usability satisfaction and engagement of digital resources. It was found that in the period 2019/2020 there was low use of the entire digital ecosystem of SE and that it was necessary to have a learning curve for users to have more autonomy to increase the use exponentially in the following year.

KEYWORDS: COVID-19. Hybrid education. Educational technologies. Digital learning objects. Digital platforms.

\section{Introdução}

No dia 11 mar. 2020 a Organização das Nações Unidas (ONU) declarou um surto mundial de uma pandemia. A pandemia do COVID-19, também conhecida como pandemia do Coronavírus, é uma doença respiratória aguda causada pelo Coronavírus da síndrome respiratória aguda grave 2 (SARS-CoV-2). Os efeitos mundiais causados pela pandemia incluem instabilidade social, psicológica e econômica, e o encerramento de aulas presenciais em escolas de educação básica.

Como essa nova realidade da pandemia e com o isolamento social acabamos tendo alterações nos processos que antes eram realizados de forma presencial e que precisaram ser abandonados por medidas de segurança. Assim, alguns temas escolares se tornaram desafiadores e exigindo novas perspectivas como o processo de ensino-aprendizagem em tempos de pandemia, as relações virtuais entre educandos e educadores, o ensino remoto, o ensino híbrido, que dentro deste cenário histórico estão sendo latentes, extremamente relevantes e se baseiam em um novo método de se ensinar, que necessitam de respaldo e atenção de todos para ser garantido a qualidade na formação integral de um indivíduo e uma harmonia com valores, moral e ética em nossa sociedade. Nota-se de antemão que durantes este período, se faz necessária a integração da tecnologia dentro dos processos educacionais, 
não somente no trato com o educando, mas também a respeito das disposições gerais da educação, dando ênfase nas relações interpessoais que foram interrompidas devido a necessidade do isolamento social.

De acordo com a portaria $n^{0} 343$ de 17 de março de 2020, o Ministério da Educação (MEC) dispõe a substituição das aulas presenciais de caráter físico, por aulas em meio digitais (sejam quais forem as plataformas) enquanto durar a situação de pandemia da COVID-19. Neste aspecto todos os meios tecnológicos presentes como a exemplo da internet, mídias digitais, celulares, smartphones, Televisão, são fundamentais e indispensáveis neste processo. Para melhor organizar os processos educacionais durante este período de crise, o Conselho Nacional de Educação (CNE) em maio 2020 publicou parecer com orientações para a reorganização do calendário escolar de forma que o mesmo venha atender os professores e educandos, para garantir que não se perca o processo de desenvolvimento do mesmo, abrindo desta algumas exceções, como a exemplo a possibilidade de cômputo de atividades não presenciais para fins de cumprimento da carga horária mínima anual, dando validade a atividades entregues como cumprimento das mesmas, em razão da pandemia e a impossibilidade de frequência em sala de aula causada pela mesma. Porém não revogando máximas anteriores, a exemplo do que está previsto pelo $\mathrm{Art}^{\mathrm{o}} 26$ da Declaração de Direitos Humanos.

Carvalho (2020) nos diz a respeito de uma das possibilidades de enfrentamento a pandemia no quesito educação, é a inserção de meios tecnológicos nos processos, na qual ela se refere em sentido e importância como sendo essenciais para as práticas pedagógicas. Assim, garantir que o trabalho desenvolvido dentro dos processos educacionais não seja desenvolvido de maneira bancária como Freire (2011) vem nos expor, e sim trazer significado precisamos buscar entender como mediar essas relações e estas questões em períodos atípicos, quando a pessoalidade não se pode fazer presente. como nos diz Moreira e Schlemmer (2020).

No parecer $n^{\circ} 30 / 2000-C N E / C E B$, sistemas de ensino são o conjunto de campos de competências e atribuições, voltadas para o desenvolvimento da educação escolar que se materializam em instituições, órgãos executivos e normativos, recursos e meios articulados pelo poder público competente, abertos ao regime de colaboração e respeitadas as normas gerais vigentes (BRASIL, 2015).

Ao longo do Ensino Fundamental - Anos Finais, os estudantes se deparam com desafios de maior complexidade, sobretudo devido à necessidade de se apropriarem das diferentes lógicas de organização dos conhecimentos relacionados às áreas. Tendo em vista essa maior especialização, é importante, nos vários componentes curriculares, retomar e 
ressignificar as aprendizagens do Ensino Fundamental - Anos Iniciais no contexto das diferentes áreas, visando ao aprofundamento e à ampliação de repertórios dos estudantes. Nesse sentido, também é importante fortalecer a autonomia desses adolescentes, oferecendolhes condições e ferramentas para acessar e interagir criticamente com diferentes conhecimentos e fontes de informação (BRASIL, 2018, 60).

O presente estudo tem por objetivo investigar o planejamento pedagógico, as metodologias de aprendizagem utilizadas e as práticas de uso do ecossistema digital durante o ensino remoto vinculado a gestão do ensino híbrido em um sistema de ensino no seguimento do Ensino Fundamental Anos Finais.

\section{Material e Métodos}

O presente estudo abarca uma pesquisa documental, no qual se norteia na investigação e exploração de diversas informações sobre a natureza e as características da análise de conteúdos que aglutinam a coleta de dados, classificação, seleção difusa e utilização de toda a espécie de informações, compreendendo também as técnicas e os métodos que facilitam sua busca e sua identificação.

A análise de conteúdo constitui uma metodologia de pesquisa usada para descrever e interpretar o conteúdo de toda classe de documentos e textos. Essa análise, conduzindo a descrições sistemáticas, qualitativas ou quantitativas, ajuda a reinterpretar as mensagens e a atingir uma compreensão de seus significados num nível que vai além de uma leitura comum.

Segundo Olabuenaga e Ispizúa (1989), a análise de conteúdo é uma técnica para ler e interpretar o conteúdo de toda classe de documentos, que analisados adequadamente nos abrem as portas ao conhecimento de aspectos e fenômenos da vida social de outro modo inacessíveis.

A matéria-prima da análise de conteúdo pode constituir-se de qualquer material oriundo de comunicação verbal ou não-verbal, como cartas, cartazes, jornais, revistas, informes, livros, relatos autobiográficos, discos, gravações, entrevistas, diários pessoais, filmes, fotografias, vídeos etc. Contudo os dados advindos dessas diversificadas fontes chegam ao investigador em estado bruto, necessitando, então ser processados para, dessa maneira, facilitar o trabalho de compreensão, interpretação e inferência a que aspira a análise de conteúdo.

Dentre as fontes de dados do sistema de ensino investigaremos o Manual de Orientações Gerais (MOG) versões 2020 e 2021, o Manual Pedagógico (MP) 2020 e 2021, os 
materiais de professores e alunos da rede privada do sistema de ensino, relatórios gerenciais das plataformas digitais e gráficos.

O MOG apresenta as informações relativas às soluções educacionais (materiais didáticos e serviços) da rede que contemplam: descrição, estrutura, composição, datas de remessa e de uso etc. O MOG é um documento que norteia o dia a dia das escolas na aplicação do sistema didático em sua totalidade e prevê possíveis dificuldades na implantação e aplicação. Já o Manual Pedagógico do sistema de ensino apresenta a fundamentação teórica das soluções educacionais, oferecendo às escolas subsídios importantes para o cumprimento do currículo.

Para tanto, este manual está organizado em quatro seções. A primeira apresenta a fundamentação legal e oficial referente à Educação Básica, indicando a documentação pública e os dispositivos legais que encaminham a coleção dos Anos Finais do ensino fundamental. Além desses aspectos, são apresentados os pilares pedagógicos das soluções didáticas.

O material do professor e do material do aluno da coleção Infinito dos Anos Finais do ensino fundamental contém toda a parte de objetos de aprendizagens e/ou conteúdos das disciplinas que estão contidas na Base Nacional Comum Curricular (BNCC) dos Anos Finais do ensino fundamental.

Os dados foram levantados em ambientes eletrônicos disponíveis na página do Sistema de ensino, bem como informações que o sistema de ensino forneceu através de sua equipe de consultoria pedagógica, consultoria comercial, equipe de analistas de sistemas digitais e consultores de tecnologias educacionais que atuam sobre todo o ecossistema pedagógico e digital (mandala) de todos os recursos digitais de plataformas do sistema de ensino.

A pesquisa ainda analisa o andamento das ações e/ou atuação do sistema de ensino durante o período pandêmico para com as suas unidades de escolas parceiras de educação básica. Fomentou-se pesquisar sobre o planejamento pedagógico do sistema de ensino diante do cenário pandêmico, o alinhamento a Base Nacional Comum Curricular (BNCC) e as práticas pedagógicas de ensino-aprendizado durante o ensino remoto, gestão do ensino híbrido e metodologias ativas aplicadas dentro deste contexto que visam promover aprendizagem de qualidade, satisfação de usabilidade e engajamento sobre as plataformas e recursos digitais disponíveis a comunidade escolar do sistema de ensino.

A relevância e escolha deste estudo se dá pela atuação expressiva que o sistema de ensino tem no cenário educacional privado, contando com mais de 800 escolas parceiras presentes em 25 estados e com mais de 210 mil alunos. O estudo dará ênfase na análise 
referente aos anos finais do ensino fundamental $\left(6^{\circ}, 7^{\circ}, 8^{\circ}\right.$ e $9^{\circ}$ ano), investigando o planejamento pedagógico e as práticas utilizadas durante o ensino remoto vinculado ao ensino híbrido e as metodologias ativas.

Os Anos Finais do Ensino Fundamental da rede do sistema de ensino possuem a coleção de materiais didáticos chamada Infinito que é uma solução educacional híbrida, que favorece a aprendizagem interdisciplinar por meio de conteúdos didáticos impressos e digitais. A integração entre conteúdo digital e impresso ocorre por meio de uma plataforma digital de aprendizagem, que traz conteúdo multimídia interativo, avaliações, relatórios e planos de aula com orientações ao professor e propostas metodológicas, incluindo abordagem expositiva tradicional, aprendizagem ativa e desenvolvimento de projetos. Além disso, a plataforma traz oportunidades de avaliação formativa e relatórios que permitem diagnósticos rápidos, precisos e relevantes que podem subsidiar intervenções pedagógicas específicas. $\mathrm{O}$ material impresso da coleção é dividido em quatro remessas e com a programação distribuída ao longo de 30 semanas, conforme o calendário pedagógico.

Com mais de 58 anos de atuação no mercado privado da educação básica brasileira o sistema de ensino pesquisado alia tradição, pioneirismo em tecnologia e qualidade de ensino, sendo sinônimo de sucesso e referência no setor educacional brasileiro. Fundado em 1963 em Ribeirão Preto (SP), o sistema de ensino possui mais de 800 escolas parceiras em todo o Brasil. Além disso, está presente na vida dos alunos durante todas as fases do ciclo educacional, da educação infantil ao pré-vestibular. Desde 1994, com a chegada dos microcomputadores ao Brasil, a rede do Sistema de Ensino já utilizava a informática para explorar todo o potencial da tecnologia na educação. Hoje o sistema de ensino leva aos alunos de suas escolas um ensino ainda mais multiconectado, repleto de soluções educacionais e conteúdos digitais que o ajudam a se preparar não só para o vestibular, mas para a vida inteira. Assim, o sistema alcançou uma geração de alunos que pensa diferente, age diferente e pede um modelo diferente de escola, que esteja ainda mais presente na vida do aluno.

A rede do Sistema de Ensino também estimula e apoia o crescimento sustentável das instituições de ensino parceiras, que nos ajudam a transformar a vida de milhares de crianças e jovens através de uma educação de excelência. Por isso, as escolas parceiras deste sistema contam com soluções empresariais, consultorias de mercado, assessoria de marketing e uma equipe comercial e pedagógica antenada com as tendências do mercado de educação. 


\section{Resultados e Discussão}

O referido sistema de ensino atua em toda a Educação Básica, composta pela Educação Infantil, pelo Ensino Fundamental e pelo Ensino Médio. De acordo com a Lei de Diretrizes e Bases da Educação Brasileira, seção I, artigo 22, “A Educação Básica tem por finalidades desenvolver o educando, assegurar-lhe a formação comum indispensável para o exercício da cidadania e fornecer-lhe meios para progredir no trabalho e em estudos posteriores".

Assim, as soluções educacionais do Sistema de ensino auxiliam a escola a promover essa formação integral do aluno. Para tanto, o Sistema vale-se de orientações presentes em documentos oficiais, descritos a seguir, que dão suporte à elaboração de sua proposta pedagógica.

Lei de Diretrizes e Bases da Educação Brasileira (LDB). Proposta do sistema de ensino: organização e estrutura dos materiais de cada segmento (BRASIL, 1996).

Diretrizes Curriculares Nacionais para a Educação Básica (DCN). Proposta do sistema de ensino: definição da estrutura e organização dos materiais, das modalidades e instrumentos de avaliação e dos princípios pedagógicos (BRASIL, 2013).

Base Nacional Comum Curricular (BNCC). Proposta do sistema de ensino: seleção de unidades e objetos do conhecimento que organizam os conteúdos de cada disciplina e definem as habilidades trabalhadas no material e indicadas na programação de conteúdo. Não obstante, nossas soluções oferecem um rol de conteúdos que supera o conjunto de conteúdos e aprendizagens essenciais prescritos pela Base Nacional Comum Curricular (BRASIL, 2017).

Referencial Curricular Nacional para a Educação Básica (RCNEI). Proposta do sistema de ensino: definição da rotina escolar sugerida e encaminhamento pedagógico (Brasil, 1998).

Parâmetros Curriculares Nacionais (PCN). Proposta do sistema de ensino: definição do tratamento didático das disciplinas e encaminhamento pedagógico dos conteúdos (BRASIL, 1997).

$\mathrm{Na}$ Coleção Infinito (material didático) dos Anos Finais, é proposto um modelo particular de avaliação formativa, aplicado em uma seção editorial denominada Para conferir, cuja aplicação prevê a possibilidade de relatórios instantâneos serem gerados por uma plataforma on-line de aprendizagem.

Para Luckesi (2011) avaliação da aprendizagem é uma prática rigorosa de acompanhamento do educando, tendo em vista sua aprendizagem e, consequentemente, o seu 
desenvolvimento. Por isso, as regras da metodologia científica devem orientar--nos na elaboração e uso de instrumentos de coletas de dados. [...] Ela [a avaliação da aprendizagem] permite tomar conhecimento do que se aprendeu e do que não se aprendeu a reorientar o educando para que supere suas dificuldades e carências, visto que o importante é aprender.

Ainda de acordo com Luckesi (2011) descreve-se o desempenho da aprendizagem dos educandos por meio de uma coleta de dados, tendo como indicadores relevantes as decisões tomadas na elaboração do projeto político-pedagógico da escola e nos planejamentos de ensino - ou seja, aquilo que se decidiu ensinar (conteúdos) e a forma como se decidiu ensinar (proposta pedagógica); 2. A seguir, qualificam-se os resultados obtidos por meio de uma comparação do desempenho descrito com os critérios de qualidade estabelecidos com base nos indicadores de ensino-aprendizagem, estabelecidos no projeto pedagógico e nos planos de ensino, possibilitando ou o diagnóstico do processo ou a certificação do resultado final em termos de aprendizagem; 3. Por último, se necessário, na avaliação de acompanhamento, pratica-se uma intervenção para a correção da ação em curso cujo, objetivo é garantir a construção satisfatória das aprendizagens almejadas dos educandos.

A proposta de ensino híbrido do sistema de ensino oferece oportunidades de alternar e integrar momentos presenciais e remotos (on-line), atividades individuais e coletivas, estratégias de aprendizagem ativa e métodos clássicos. Desse modo, as variadas formas de interação com o conteúdo devem ser integradas em uma experiência coesa para o aluno.

Para isso, os componentes on-line da experiência de aprendizado consistem em exercícios e conteúdos adicionais que aperfeiçoam o desenvolvimento da aula presencial, por exemplo, com o uso de Objetos Digitais de Aprendizagem (ODA) e geração de relatórios de avaliação formativa. Essa integração promovida pelo ensino híbrido do sistema de ensino não reduz o tempo de contato presencial entre professor e aluno, nem transfere parte significativa da relação ensino-aprendizagem para ambientes on-line.

Segundo Moran (2015) híbrido significa misturado, mesclado, “blended”. A educação sempre foi misturada, híbrida, sempre combinou vários espaços, tempos, atividades, metodologias, públicos. Esse processo, agora, com a mobilidade e a conectividade, é muito mais perceptível, amplo e profundo: é um ecossistema mais aberto e criativo.

Para Horn e Staker (2015) ensino híbrido é um programa de educação formal no qual um aluno aprende, pelo menos em parte, por meio do ensino on-line, com algum elemento de controle do estudante sobre o tempo, o lugar, modo e/ou ritmo do estudo, e em parte em uma localidade física supervisionada fora de sua residência. 
O conteúdo teórico estruturado em hipertexto permite organizar blocos de informação em percursos alternativos de leitura. Assim, a sequência associativa comum, tradicionalmente predefinida e fixa, é relativizada.

A associação entre os blocos de informação é garantida pelo uso de recursos visuais de marcação: vinheta e ícone. As vinhetas identificam tipos de blocos textuais organizados em compartimentos de informação, denominados boxe.

Os ícones, por sua vez, são miniaturas simplificadas das vinhetas, responsáveis pela remissão recíproca entre texto principal e secundário, garantindo, assim, hiper ligações entre os blocos de informação.

O projeto gráfico-editorial apresenta, portanto, uma organização hipertextual que explora a potencialidade da integração digital e impresso através de boxes ligados ao conteúdo principal, como pode ser notado neste exemplo de Arte, extraído do sexto ano.

Figura 1 - Organização hipertextual (vinhetas e ícones)

Fonte: Manual pedagógico do sistema de ensino (2021)

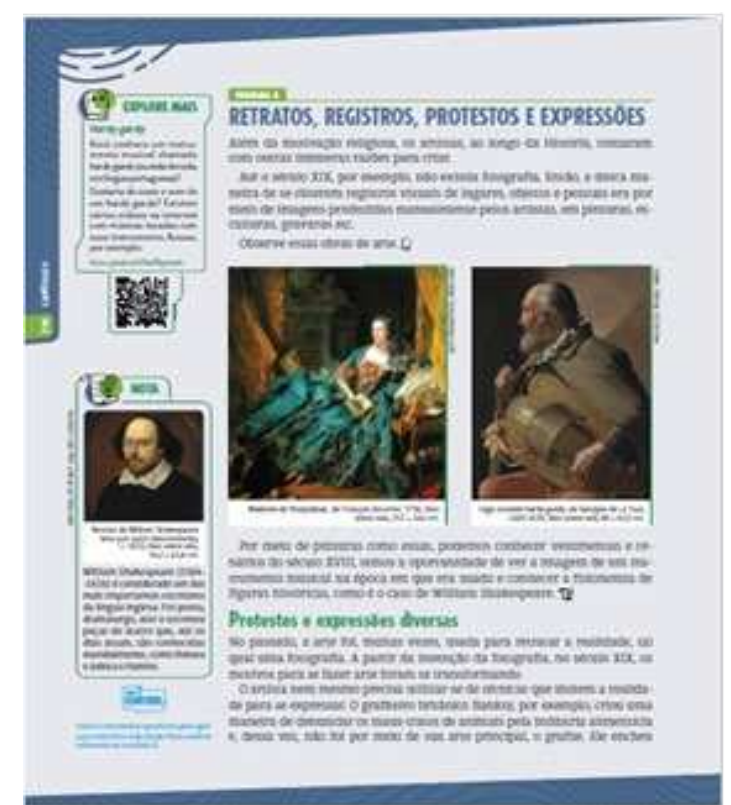

Diversos tipos de boxes e marcadores de conteúdo são aplicados com a intenção de organizar visualmente os conteúdos oferecidos no hipertexto como mostra a figura abaixo: 
Figura 2 - Boxes, ícones e selos

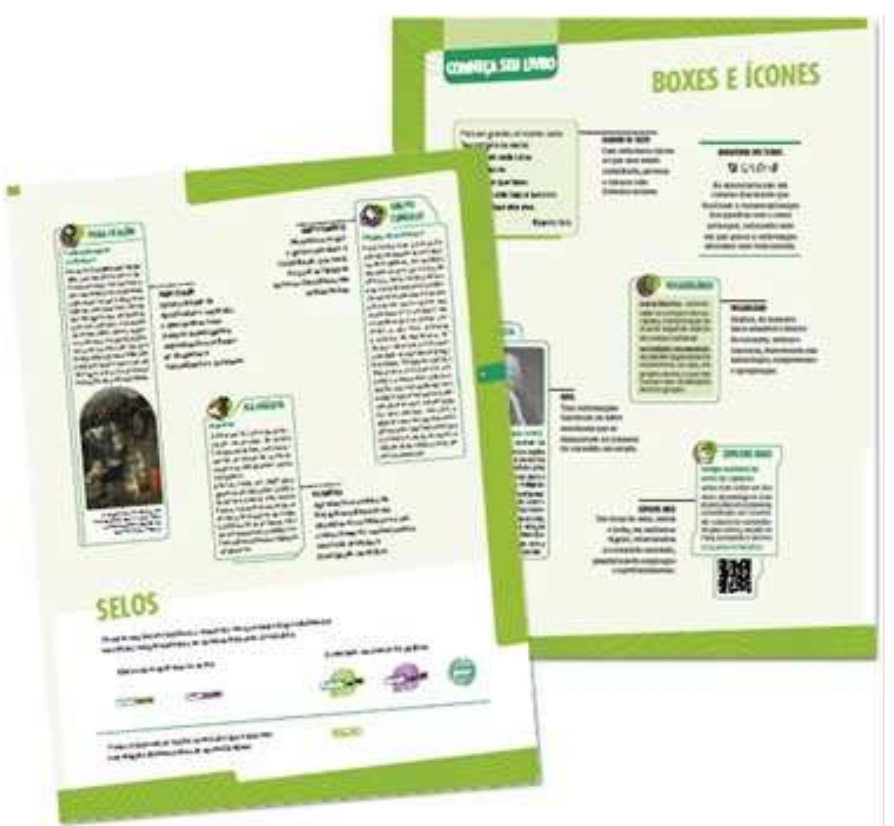

Fonte: Manual pedagógico do sistema de ensino (2021)

A proposta de ensino híbrido oferece conteúdos, ferramentas e recursos complementares vinculados aos livros impressos, para instrumentalizar o professor e apoiá-lo na preparação e na execução das aulas, potencializando, assim, o uso da coleção.

A integração entre os elementos da solução ocorre por meio de uma plataforma digital de gerenciamento de aprendizagem e oferta de conteúdo: a plataforma Infinito.

Para cada sequência didática, correspondente a um ou mais módulos, é sugerido um plano de aula, apresentado em uma página única e com cinco seções fixas cronometradas: introdução, conceituação, ampliação, sistematização e fixação. O plano de aula traz, sempre que possível, alternativas técnicas e sugestões para os professores aperfeiçoarem suas aulas, como uso de tecnologias, técnicas de aprendizagem ativa e sugestões para aula clássica. 
Figura 3 - Exemplo de plano de aula

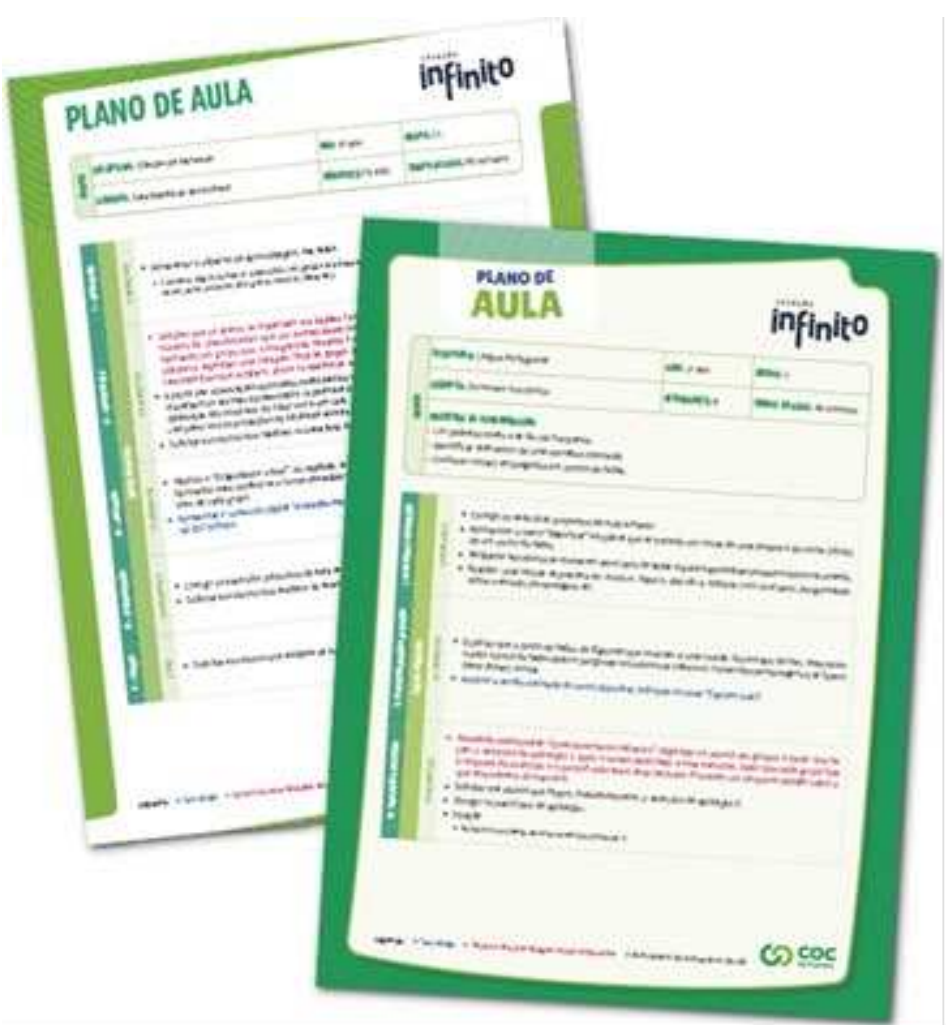

Fonte: Manual pedagógico do sistema de ensino (2021)

Os conteúdos digitais disponíveis no Portal do sistema de ensino frequentemente são referidos nos materiais impressos por meio de códigos QR. Nele o aluno e o professor têm acesso a atualidades, curiosidades, aprofundamento, dicas, entre outros conteúdos.

São disponibilizados 60 objetos digitais de aprendizagem para cada ano, em diversos formatos, cujos roteiros exploram textos verbais e não verbais concebidos e planejados para apoiar a prática pedagógica, tanto na sala de aula como em outros espaços. A seguir, estão listados os três principais tipos e subtipos de objeto digital, com base em diferentes combinações de roteiros e recursos audiovisuais.

- Narrativa audiovisual.

- Animação interativa e não interativa.

- Motion graphic, infografia interativa e conteúdo exploratório.

- Minidocumentário (legendado ou para listening).

- Demonstração, simulação e experimentação.

- Jogo eletrônico (game). 
Para garantir maior liberdade didática no planejamento pedagógico e no uso em aula desses recursos, a disponibilidade desses objetos é notificada na programação e no livro impresso através de um ícone visível apenas para o professor.

Além disso, no sentido de subsidiar pedagogicamente o docente, os objetos digitais de aprendizagem estão sempre ligados aos objetivos descritos na abertura da disciplina e também relacionados às habilidades disponíveis na programação.

Exercícios inseridos na plataforma Infinito podem ser realizados em casa ou durante a aula, gerando, em ambos os casos, relatórios e dados que podem ser utilizados para diversos formatos de avaliação.

A plataforma oferece ainda a versão digital do material impresso e do manual do professor, fórum de discussão, caixa de mensagem, bate-papo, calendário, notificação de atualização e alerta, progresso da aula, relatórios de uso etc.

Notamos que com a liberação do ensino remoto nas escolas de educação básica a utilização do ecossistema digital do sistema de ensino cresceu de forma exponencial com uma escalabilidade de acessos comparados e representados nos 3 gráficos a seguir. As informações foram fornecidas pelo time de inteligência e performance de mercado do sistema de ensino.

Figura 4 - Acessos ao ecossistema digital do sistema

\section{QUANTIDADE DE ACESSOS}

20000

18000

16000

14000

12000

10000

8000

6000

4000

2000

0

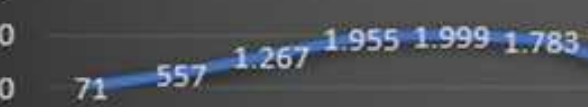
15 $1.947^{2.416-2.312-2.294}$

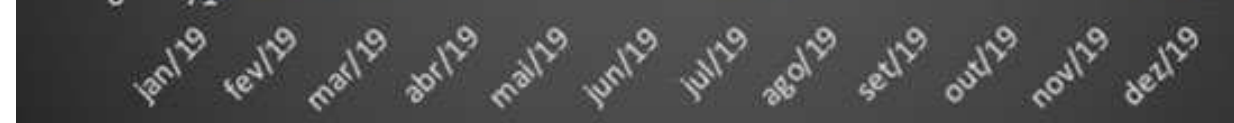

Nota: *valor correspondente ao período de janeiro à dezembro de 2019. Acessos a plataformas digitais.

Fonte: Departamento performance e inteligência de mercado do sistema de ensino (2019) 
Na Figura 4 temos a representação dos acessos do ano de 2019, no qual ainda não estávamos em período pandêmico e percebemos que o engajamento e utilização de professores e alunos dos recursos digitais do sistema de ensino não vinham sendo utilizados de acordo com a proposta da coleção do material didático que é inerente e se complementa com os recursos de gestão híbrida.

Abaixo temos a Figura 5 que abarca o ano de 2020, no qual o período pandêmico iniciou-se de forma oficial a partir do mês de março.

Figura 5 - Acessos ao ecossistema digital do sistema

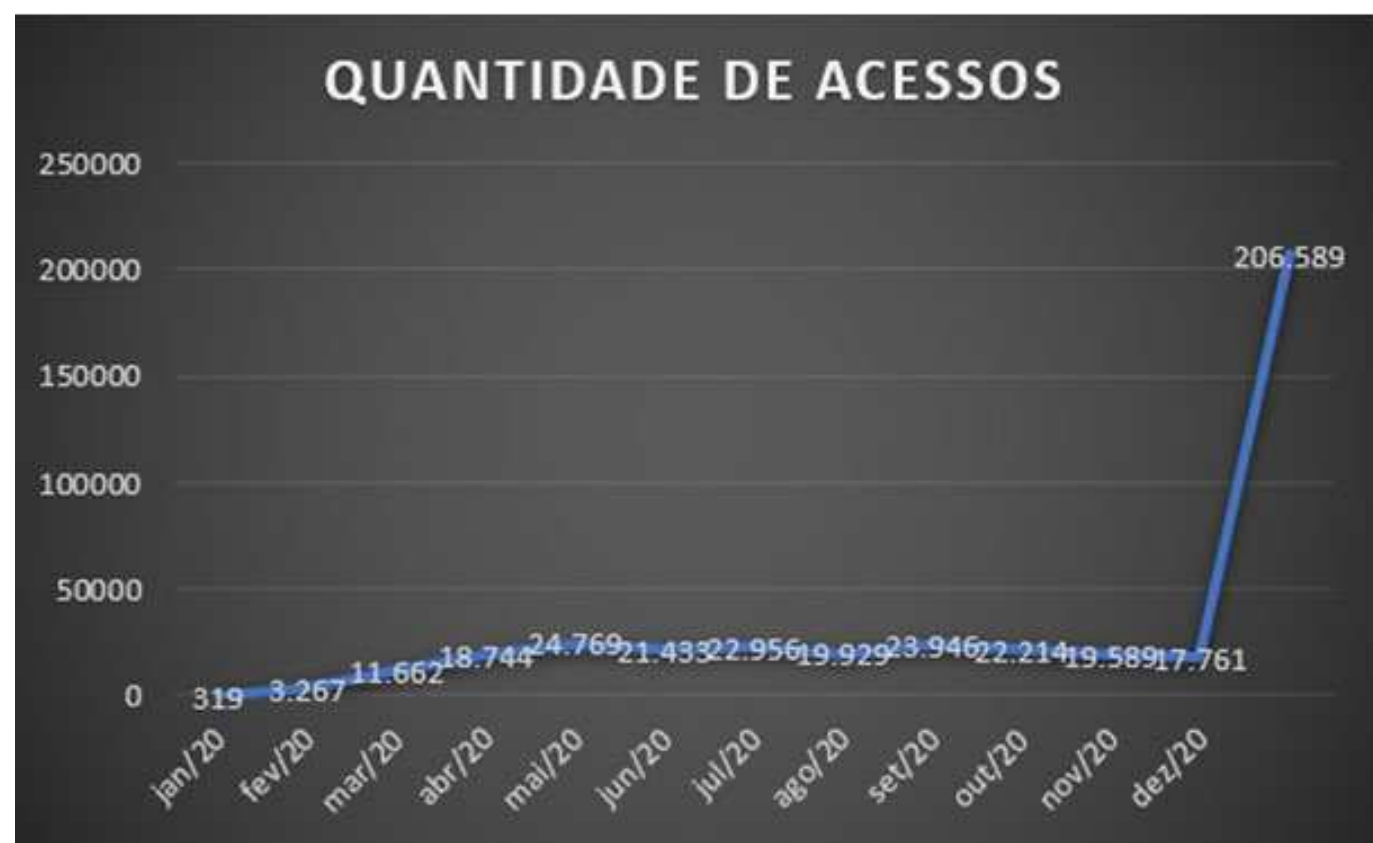

Nota: *valor correspondente ao período de janeiro à dezembro de 2020. Acessos a plataformas digitais.

Fonte: Departamento performance e inteligência de mercado do sistema de ensino (2020)

Na Figura 5 temos um gráfico, no qual notamos que mesmo estando em um período de pandemia a utilização do ecossistema digital do sistema de ensino não emplacou de forma significativa com o ensino remoto em relação a quantidade de escolas $\mathrm{x}$ alunos, e apenas no mês de dezembro tivemos um surto de acessos da gestão pedagógica, professores e alunos.

Nota-se um aumento considerável no mês de dezembro de 2020 que corresponde a necessidade do fechamento do semestre. Com isso, alunos, professores e gestores educacionais acabam tendo uma assiduidade maior nas plataformas e recursos digitais para efetuarem o cumprimento de todo o conteúdo, avaliações e fechamento de notas.

Por fim abaixo temos a figura 6 que consiste na representação gráfica do ano de 2021 e que nos traz expressividades nos números representados, no qual segue abaixo: 
Figura 6 - Acessos ao ecossistema digital do sistema

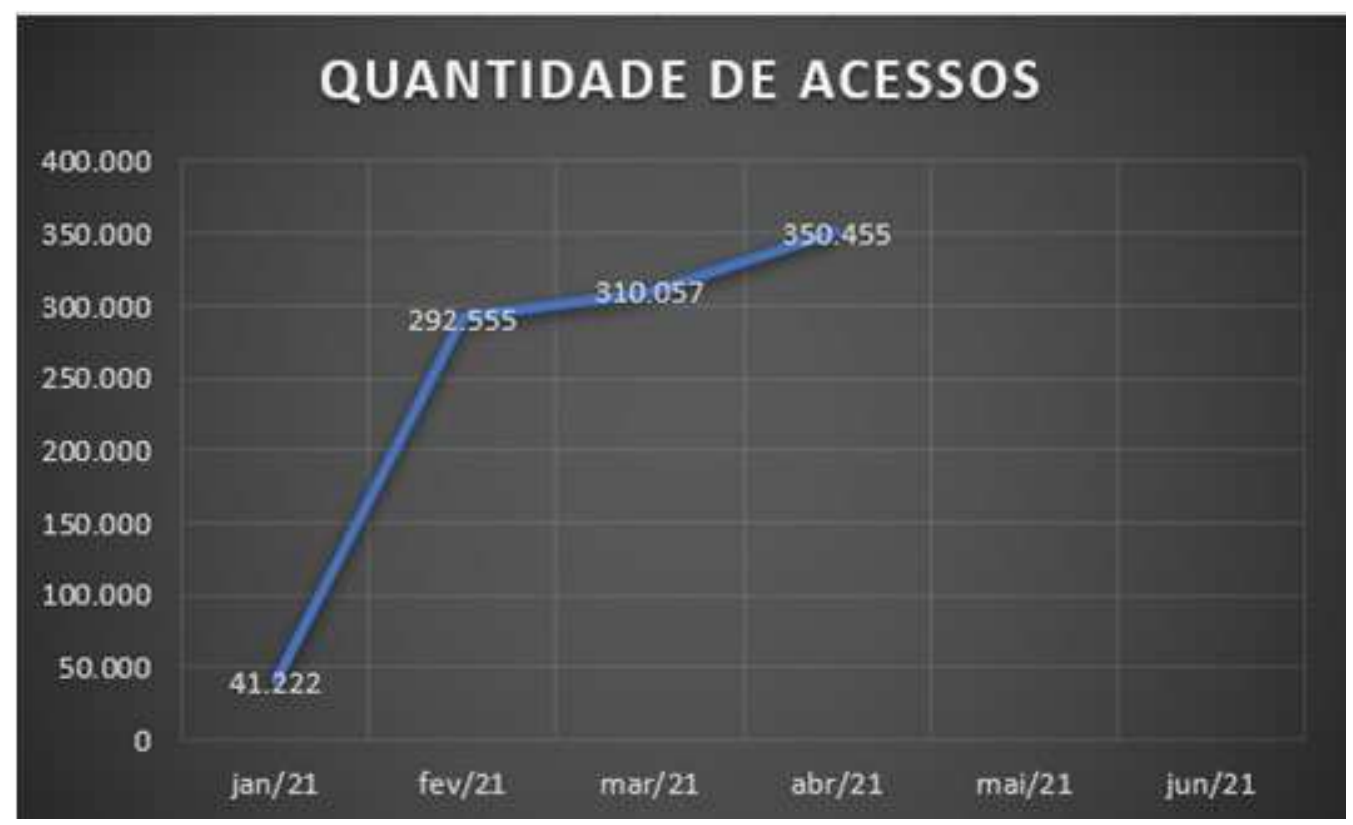

Nota: *valor correspondente ao período de janeiro à abril de 2021. Acessos a plataformas digitais.

Fonte: Departamento performance e inteligência de mercado do sistema de ensino (2021)

Na Figura 6 que é representada pelo gráfico referente ao ano vigente em que ainda estamos em um período pandêmico percebemos que diferente dos anos anteriores o engajamento e utilização do ecossistema digital, bem como a gestão do ensino híbrido que comunga com a proposta pedagógica do sistema de ensino emplacou de vez e agora temos um fluxo de utilização que mostra que as escolas do sistema de ensino estão mais adaptadas e realmente tiveram que aderir a proposta pedagógica como um todo fazendo com que o sentido de equivalência da gestão pedagógica do sistema de ensino tenha sentido e funcione bem no processo de ensino aprendizagem.

De acordo com Cordeiro (2020) a crise do novo corona vírus terá efeitos perenes e permanentes sobre a forma de aprender e de se ensinar, já que gerou novas maneiras de se observar determinadas situações, pois devido ao isolamento social, novos hábitos e comportamentos estão sendo criados para a adaptação a essa nova realidade, lembrando que realidades diferentes exigem ações e práticas renovadas, tanto nas famílias, quanto nas instituições de ensino, que estão revendo uma série de processos, conceitos, estruturas e metodologias. Aprendemos que lidar com a imprevisibilidade e com casos de excepcionalidade, exige um trabalho em grupo muito mais alinhado e consistente que, mesmo distantes fisicamente, incapazes de estarmos presentes, podemos unir esforços em prol de um bem maior a educação e os processos necessários para que ela continue seu fluxo. 
Outro aspecto muito importante a ser abordado é a questão social, pensar como a pandemia e seus reflexos atingem o público escolar e acabam por dificultar a vida de pais, docentes e discentes, já que a escola além de um lugar que vem para de acordo com a pedagogia histórico-crítica, transmitir o saber sistematizado e comprovado cientificamente como o mesmo destaca "aquilo que se firmou como fundamental, como essencial. Pode, pois, constituir-se num critério útil para a seleção dos conteúdos do trabalho pedagógico" (SAVIANI, 2009)

Como nos discorre Santos (2020) em seu trabalho no qual ela nos afirma que o ensino remoto tem deixado suas marcas em todos, em alguns casos, permitindo encontros afetuosos e boas dinâmicas curriculares, dando a alguns alunos e professores a possibilidade de realizarem novas atividades e garantir a saúde mental de todos, e, em outros, tem repetido modelos massivos, bancários e técnicos subutilizando os potenciais da cibercultura na educação e não dando a devida atenção a todas as possibilidades abertas por tal realidade.

Um dos principais processos do planejamento educacional consiste na comunicação com os alunos e alguns responsáveis, a fim de identificar quais aspectos precisam ser melhorados pela escola a fim de contribuir eficientemente para a evolução educacional dos alunos. A comunicação entre os gestores, professores e alunos foi apontada como um diferencial organizacional, evidenciando como ambos poderiam promover suas atividades da melhor forma possível.

Outro fator relevante no planejamento escolar durante este período de crise se refere aos objetos de aprendizagens que amparam conhecimentos, habilidades, hábitos, modos valorativos e atitudinais de atuação histórico-social, organizados pedagogicamente e didaticamente em matérias de ensino, tendo em vista o processo de construção do conhecimento pelos alunos e suas relações com o contexto vivido.

\section{Conclusão}

No decorrer deste trabalho notamos que o gráfico do ano de 2019, no qual antecede o cenário pandêmico, tivemos um baixo engajamento de uso do ecossistema digital proposto pelo sistema de ensino. Mesmo com plataformas e produtos digitais robustos ofertados pelo sistema de ensino e operando durante todo o ano de 2019 tivemos uma média mensal bem baixa de acessos de alunos e professores. Este resultado apresentado mostrou que a regularidade do uso do ecossistema digital não era um fator determinante do sistema de ensino para com suas escolas parceiras. Fica evidente que até então o sistema de ensino não 
reivindicava a assiduidade de uso dos recursos disponibilizados as escolas parceiras e todo o processo educacional se mantinha concentrado em um modelo totalmente tradicional sem aderência comum as ferramentas tecnológicas de ensino e aprendizagem. No gráfico do ano de 2020, no qual a pandemia iniciou-se oficialmente no mês de março notamos que tivemos um pequeno aumento na média mensal de acessos, mas ainda não expressivo o suficiente em relação a quantidade de escolas x quantidade de alunos x quantidade de professores. $\mathrm{O}$ ano de 2020 foi um ano em que toda a comunidade escolar teve que realmente passar por uma imersão de aprendizado com o início do ensino remoto no país levando todas as escolas parceiras, gestores pedagógicos, professores, alunos e famílias do referido sistema de ensino a passaram por uma curva processual de aprendizagem para adquirirem habilidades e competências para operarem e terem sucesso na usabilidade e engajamento do ecossistema digital, pois sentiram bastante o desafio de um cenário pandêmico por não estarem totalmente preparadas para essa nova realidade, sendo necessário a capacitação e reciclagem para que pudessem colocar em prática toda a proposta pedagógica do sistema de ensino que prevê o ensino remoto e o ensino híbrido aglutinado ao uso do material didático (impresso) como um dos seus pilares na associação e integração as plataformas digitais que possuem objetos de aprendizagens que interagem com diversos tipos de metodologias ativas para uma gestão de ensino híbrido com ênfase na personalização do ensino para cada indivíduo de acordo com o perfil de aluno e necessidades a serem trabalhadas. No gráfico do ano de 2021 tivemos um aumento exponencial do uso dos recursos digitais. Após o período pautado nas curvas processuais de aprendizagens adquiridas e a determinação do sistema de ensino para a regularidade do uso de seu ecossistema digital para manter a qualidade e a documentação organizada para tratativas de equivalência com as esferas regulamentadoras oficiais, entendemos que a comunidade escolar assimilou e acomodou instancias de habilidades e competências que acabaram causando grande engajamento no pleno uso e aplicação da proposta pedagógica do sistema de ensino. A pandemia do COVID-19 trouxe diversos desafios, ensinos e aprendizagens que conseguimos entender ao longo deste trabalho que de acordo com a necessidade social uma nova transposição didática assumiu o momento deixando o mecanismo presencial para a adaptação de uma realidade de escola virtual com muitas interações entre as rotinas educativas $\mathrm{e}$ as tecnologias, um dos principais procedimentos utilizados ao longo da pandemia para estabilizar os processos da educação e minimizar a perda de qualidade no processo de ensino e aprendizagem por parte dos professores e alunos. 
AGRADECIMENTOS: Agradeço ao professor Marcos Cesar Rodrigues de Miranda, pela paciência, orientações e apoio para a construção deste trabalho que contribuiu de forma significativa no meu desempenho enquanto educando.

\section{REFERÊNCIAS}

BRASIL. Lei n. 9394 de 20 de dezembro de 1996. Lei de diretrizes e bases da educação nacional. Diário Oficial da União: Seção 1, Brasília, DF, p. 27833, col. 1, 23 dez. 1996.

BRASIL. Ministério da Educação. Secretaria de Educação Fundamental. Parâmetros Curriculares Nacionais para o Ensino Fundamental. Brasília, DF: MEC/SEF, 1997

BRASIL. Ministério da Educação. Secretaria de Educação Fundamental. Referencial Curricular Nacional para a Educação Infantil. Brasília, DF: MEC/SEF, 1998.

BRASIL. Secretária de Educação. Básica. Diretoria de Currículos e Educação Integral. Diretrizes Curriculares Nacionais da Educação Básica. Brasília, DF: MEC/SEB/DICEI, 2013.

BRASIL. Ministério da Educação. Secretaria de Educação Básica. Parecer CNE/CEB 30/2000. Brasília, DF: MEC/SEB, 2015. Disponível em:

http://portal.mec.gov.br/cne/arquivos/pdf/pceb030_00.pdf. Acesso em: 12 abr. 2021.

BRASIL. Instituto Nacional de Estudos e Pesquisas Educacionais Anísio Teixeira. Plano nacional de educação PNE 2014-2024: Linha de base. Brasília, DF: INEP, 2015. 404 p.

BRASIL. Ministério da Educação. Conselho Nacional de Secretários de Educação. União Nacional dos Dirigentes Municipais de Educação. Base Nacional Comum Curricular: Educação infantil e ensino fundamental. Brasília, DF: MEC/CONSED/UNDIME, 2017.

BRASIL. Ministério da Educação. Base Nacional Comum Curricular (BNCC). Brasília: MEC, 2018. Disponível em:

http://basenacionalcomum.mec.gov.br/implementacao/praticas/caderno-de-praticas/ensinofundamental-anos-finais/. Acesso em: 06 set. 2021.

CARVALHO, M. T. Desafios da gestão educacional no pós-pandemia. In: COSTIN, C. et al. A escola na pandemia: 9 visões sobre a crise do ensino durante o Coronavírus. Porto Alegre, RS: Ed. do Autor, 2020. p. 11-14.

CORDEIRO, K. M. A. O impacto da pandemia na educação: A utilização da tecnologia como ferramenta de ensino. 2020. Disponível em:

http://repositorio.idaam.edu.br/jspui/handle/prefix/1157. Acesso em: 06 set. 2021

FREIRE, P. Pedagogia do oprimido. 50. ed. Rio de Janeiro, RJ: Paz e Terra, 2011.

HORN, M. B.; STAKER, H. Blended: usando a inovação disruptiva para aprimorar a educação. Porto Alegre, RS: Penso, 2015.

RPGE- Revista on line de Política e Gestão Educacional, Araraquara, v. 25, n. 3, p. 2098-2116, set./dez. 2021. e-ISSN: 1519-9029 
LUCKESI, C. C. Avaliação da aprendizagem: componente do ato pedagógico. São Paulo, SP: Cortez, 2011.

MORAN, J. Educação Híbrida: um conceito-chave para a educação hoje. In: BACICH, L.; TANZI NETO, A.; TREVISANI, F. M. Ensino Híbrido: personalização e tecnologia na educação. Porto Alegre, RS: Penso, 2015. p. 27-45.

MOREIRA, J. A.; SCHLEMMER, E. Por um novo conceito e paradigma de educação digital online. Revista UFG, v. 20, n. 26, p. 1-35, 2020. Disponível:

https://www.revistas.ufg.br/revistaufg/article/view/63438. Acesso em: 10 jan. 2021.

OLABUENAGA, J. I. R.; ISPIZÚA, M. A. La descodificacion de la vida cotidiana:

métodos de investigacion cualitativa. Universidad de deusto, Bilbao, 1989.

ONU. Organização das Nações Unidas. Declaração universal dos direitos humanos de 1948. 2020. Disponível em: https://www.unicef.org/brazil/declaracao-universal-dos-direitoshumanos. Acesso em: 12 dez. 2020.

PEARSON Education do Brasil S.A. Manual de Orientações Gerais. Editora São Paulo, SP, 2020.

PEARSON Education do Brasil S.A. Manual Pedagógico. Editora São Paulo, SP, 2020.

PEARSON Education do Brasil S.A. Manual de Orientações Gerais. Editora São Paulo, SP, 2021.

PEARSON Education do Brasil S.A. Manual Pedagógico. Editora São Paulo, SP, 2021.

SANTOS, E. EAD, palavra proibida. Educação online, pouca gente sabe o que é. Ensino remoto, o que temos. Revista Docência e Cibercultura, Rio de Janeiro, ago. 2020. ISSN: 2594-9004. Disponível em: https://www.e-publicacoes.uerj.br/index.php/redoc/announcement/view/1119. Acesso em: 08 maio 2021.

SAVIANI, D. Pedagogia histórico-crítica: primeiras aproximações. 11. ed. Campinas, SP: Autores Associados, 2009. 


\section{Como referenciar este artigo}

PAULA, F. D.; MIRANDA, M. C. R. Educação e pandemı: o ensino fundamental anos finais em um sistema de ensino. Revista online de Política e Gestão Educacional, Araraquara, v. 25, n. 3, p. 2098-2116, set./dez. 2021. e-ISSN: 1519-9029. DOI: https://doi.org/10.22633/rpge.v25i3.15492

Submetido em: 13/09/2021

Revisões requeridas em: 14/10/2021

Aprovado em: $13 / 11 / 2021$

Publicado em: 08/12/2021

RPGE- Revista on line de Política e Gestão Educacional, Araraquara, v. 25, n. 3, p. 2098-2116, set./dez. 2021. e-ISSN: 1519-9029 